\title{
The Journal of Consumer Policy Outstanding Reviewer Award 2016
}

\author{
Lucia A. Reisch ${ }^{1}$
}

Received: 23 February 2016/Accepted: 18 April 2016/

Published online: 27 April 2016

(C) Springer Science+Business Media New York 2016

Over the past decades, the Journal of Consumer Policy's success is in no small measure due to the willingness of leading scholars in this field to volunteer their time, expertise, and effort to review manuscripts and provide clear feedback to both editors and authors. A few years ago, the editors of the Journal decided that we would honour the contributions made by our reviewers through establishing the Outstanding Reviewer Award. This Award recognizes a member of the editorial board who consistently provides high quality reviews of manuscripts and through these reviews has contributed to increasing the clarity, precision, and contribution of the papers published in the Journal of Consumer Policy. The recipient of this Award receives a small financial reward but the primary purpose of the Award is to recognize an oftenoverlooked contribution scholars make to their disciplines - the time invested in the peer review process.

The selection decision as to who should receive the Award is made at the annual editors meeting and is based on reviews covering the previous three years. All reviewers who have provided four or more reviews over the course of this three-year period are eligible to be considered for the award.

As with the previous recipients of this award-Pauline Ippolito, Robert Meyer, Andreas Oehler, and Iain Ramsay - the recipient of this year's Award was selected unanimously by the editors of the journal. The editors are proud to announce that, in 2016, the award goes to Associate Professor Wencke Gwozdz from Copenhagen Business School, Denmark. Wencke Gwozdz has been engaged in consumer research since her early days of her career. Although her career is still young, she has already established an impressive track record of contributions to academic journals and edited collections.

Prior to joining Copenhagen Business School in 2008, she studied at the University of Hohenheim in Germany where she also completed her $\mathrm{PhD}$ in economics. Her main areas of expertise are quantitative methods of consumer research, public health research and sustainable consumption. She engages in interdisciplinary large-scale research projects where she

Lucia A. Reisch

lr.ikl@cbs.dk

1 Department of ICM/cbsCSR, Copenhagen Business School, Porcelaenshaven 18a, 2000 Frederiksberg, Denmark 
successfully collaborates with other researchers at the boundaries between the social sciences, the humanities, and the life sciences.

In keeping with the Journal of Consumer Policy's approach, Professor Gwozdz's work is interdisciplinary and empirical. She joined the Editorial Board in 2012. The nature of her expertise means that the Journal's economics and social science editors often rely on Wencke as a reviewer for new submissions. Her helpful and timely comments are always of great benefit both to us as editors and to authors alike.

We are deeply grateful for her reliable and supportive service to and engagement with the journal. Without our dedicated reviewers, an academic journal such as JCP could not thrive.

The Editors

Alan Mathios, Cornell

Hans-W. Micklitz, Florence

Lucia A. Reisch, Copenhagen

John Thøgersen, Aarhus

Christian Twigg-Flesner, Hull 